\title{
A new species of Paramunida Baba, 1988 from the Central Pacific Ocean and a new genus to accommodate $P$. granulata (Henderson, I 885)
}

\author{
Patricia Cabezas', Enrique Macpherson ${ }^{2}$ \\ I Smithsonian Institution, National Museum of Natural History, Department of Invertebrate Zoology, Museum \\ Support Center, MRC 534, 4210 Silver Hill Road. Suitland, MD 207462 Centre d'Estudis Avançats de Blanes \\ (CEAB-CSIC), C. d'Accés Cala Sant Francesc 14, 17300 Blanes, Spain
}

Corresponding author: Patricia Cabezas (pcabezaspadilla@gmail.com)

Academic editor: Niel Bruce | Received 13 May 2014 | Accepted 26 June 2014 | Published 10 July 2014

http://zoobank.org/CE1C5067-967C-409C-A683-2CBE76653210

Citation: Cabezas P, Macpherson E (2014) A new species of Paramunida Baba, 1988 from the Central Pacific Ocean and a new genus to accommodate P. granulata (Henderson, 1885). ZooKeys 425: 15-32. doi: 10.3897/zookeys.425.7882

\begin{abstract}
The genus Paramunida belongs to the most diverse family of galatheoids and it is commonly reported from the continental slope across the Indian and Pacific Oceans. Examination of material collected by the NOAA RV Townsend Cromwell Cruise near Christmas (Kiritimati) Island, Kiribati, revealed the existence of a new species of Paramunida (P. haigae), which represents the fourth record of the genus for the Central Pacific. Furthermore, recent efforts to unravel phylogenetic relationships and diversification patterns in Paramunida revealed P. granulata (Henderson, 1885) to be the most basally diverging taxon within the genus. This species is clearly distinguished from other species of Paramunida by the spinulation of the carapace and the length of the distomesial spine of the second antennal peduncle article, which in combination with a high level of genetic divergence suggest that this species represents a separate monotypic lineage. A new genus, Hendersonida gen. n., is proposed to accommodate this species based on morphological and molecular evidence. An updated dichotomous identification key for all species of Paramunida is presented.
\end{abstract}

\section{Keywords}

New species, Paramunida, new genus, Hendersonida, Munididae, squat lobster, morphology, phylogeny 


\section{Introduction}

Squat lobsters are abundant and highly visible crustaceans in the deep sea (Baba et al. 2008). Our understanding of the taxonomy and phylogeny of this speciose group has been revolutionized in the last three decades, mainly thanks to the numerous MUSORSTOM-TDSB expeditions (Richer de Forges et al. 2013). Major rearrangements at higher classifications (Ahyong et al. 2010; Schnabel and Ahyong 2010), the description of 14 new genera (Macpherson and Baba 2011; Macpherson and Robainas-Barcia 2013) and many new species (Baba 2005) demonstrate the outstanding efforts of taxonomists to accurately describe and interpret squat lobster diversity.

The genus Paramunida Baba, 1988, recently transferred to the family Munididae (Ahyong et al. 2010), was established by K. Baba to accommodate seven species morphologically close to Munida Leach, 1820, but characterized by having a shortrostrum, carapace covered with spinules or granules, indistinct transverse striae, a well-developed distomesial spine on the first article of the antennal peduncle and the male gonopods present only on the second abdominal somite. In following years, several species were described from New Caledonia and adjacent waters (e.g., Cabezas et al. 2009; Macpherson 1993, 1996) and the most recent taxonomic revisions revealed the surprising existence of 14 new species (Cabezas and Chan 2014; Cabezas et al. 2010).

The genus includes 40 genetically distinct yet morphologically very similar species (Cabezas et al. 2010). Interestingly, the species Paramunida granulata (Henderson, 1885) is unique in having a granulated carapace and the distomesial spine of antennal article 2 very long, almost reaching the end of the anterior prolongation of article 1 (Baba 1988; Cabezas et al. 2010). A previous phylogenetic study reported this species as the earliest offshoot within the genus in the early Oligocene (Cabezas et al. 2012), which along with the above-mentioned marked morphological differences and a high genetic divergence indicate that this species followed an independent evolutionary trajectory (Cabezas et al. 2010; Cabezas et al. 2012; Machordom and Macpherson 2004). To reflect these findings, we herein propose a new genus, Hendersonida gen. $\mathrm{n}$.

Furthermore, during a recent visit to Los Angeles County Museum of Natural History, some Paramunida specimens previously identified as Munida hawaiiensis (Baba, 1981) were discovered to be an undescribed species. The material examined was collected by the NOAA ship RV Townsend Cromwell in Christmas (Kiritimati) Island, Kiribati, in the Central Pacific Ocean. To date, only the endemic species $P$. hawaiiensis (Baba, 1981) from Hawaii, P. spatula Macpherson, 2006 from the Austral Archipelago and P. echinata Macpherson, 1999 from the Marquesas Islands are known from Central Pacific waters. Therefore, the new species described here is the fourth record of the genus for the region. Finally, we present an updated dichotomous key to species of Paramunida. 


\section{Material examined}

We studied material collected by the NOAA RV Townsend Cromwell Cruise during February-March 1973 in the Central Pacific Ocean. The new described species in this study is deposited in Los Angeles County Museum of Natural History, Los Angeles (LACM). The terminology used mainly follows Baba et al. (2011). The size of the carapace is indicated as the postorbital carapace length measured along the dorsal midline from the posterior margin of the orbit to the posterior margin of the carapace. The length of the antennular and antennal articles is measured excluding distal spines along their lateral margins; the width is measured at midlength of each article. The abbreviations used are: P1 = first pereopod (chelipeds), P2-P4 = second to fourth pereopods (first to third walking legs).

\section{Molecular data}

The phylogenetic tree presented in this study was obtained from Cabezas and Chan (2014). The new species described here failed amplification because material was preserved in formalin, so no molecular comparison is provided.

\section{Family Munididae Ahyong, Baba, Macpherson \& Poore, 2010}

\section{Genus Paramunida Baba, 1988}

Paramunida Baba, 1988: 175 (gender: feminine). - Poore 2004: 239. - Baba 2005: 197. - Baba et al. 2008: 171 (compilation of species). - Baba et al. 2009: 277. - Cabezas et al. 2010: 5. - Macpherson and Baba 2011: 60.

Diagnosis. (modified from Baba et al. 2009) Carapace as long as wide; dorsal surface covered with spinules, indistinct transverse striae; posterior margin with some spines; rostrum short, basally subtriangular, distally ending in spine; supraocular spines small, clearly not reaching midlength of rostrum and falling short the end of the corneae; margin between rostral and supraocular spines straight or slightly concave; anterolateral spines well developed at front near anterolateral angles, reaching the level between rostrum and supraocular spines; lateral margins with some spines. Eyes large, maximum corneal diameter about one-third distance between anterolateral spines. Lateral margin of antennular article 1 with distal slender portion about half as long as proximal inflated portion, with 2 distal small spines. Antennal peduncle with anterior prolongation of article 1 spiniform; article 2 with distomesial spine never reaching end of anterior prolongation of article 1 . $\mathrm{P} 1-\mathrm{P} 4$ long and slender, squamate; P2-P4 dactyli slender, curved and unarmed on flexor margin. Male gonopods only present on the second abdominal somite. 
Type species. Paramunida setigera Baba, 1988; by original designation.

Remarks. The Munida scabra group was recognized by K. Baba in 1981. It included five species - M. scabra (Henderson, 1885), M. granulata (Henderson, 1885), M. proxima (Henderson, 1885), M. tricarinata (Alcock, 1894) and M. hawaiiensis (Baba, 1981) - all characterized by having a short rostrum, carapace without transverse ridges covered by spinules and granules, the antennal peduncle with a well-developed anterior prolongation of article 1 , and male gonopods absent from first abdominal somite. All these peculiarities suggested that the scabra group represented an independent lineage from Munida, but further investigations were recommended. Later work confirmed the taxonomic significance of this group and the genus Paramunida Baba, 1988 was formally described in a report on the chirostylid and galatheid crustaceans from the "Albatross" Philippine Expedition (Baba 1988). This new genus accommodated the species belonging to the scabra group plus two new described species $P$. longior and $P$. setigera. Paramunida was substantially enlarged through the MUSORSTOMTDSB expeditions in waters around the Philippines, Indonesia and New Caledonia (Macpherson 1993; Baba 2005), Wallis and Futuna (Macpherson 1996), eastern Australia (Ahyong and Poore 2004), Fiji and Tonga (Macpherson 2004), French Polynesia (Macpherson 2006), New Zealand (Ahyong 2007), Taiwan and Japan (Baba et al. 2009; Macpherson and Baba 2009), and the Solomon Islands (Cabezas et al. 2009). Most recently, the taxonomic revision of the genus resulted in the description of 11 new species (Cabezas et al. 2010), and examination of material collected during the PANGLAO expeditions added three new ones namely $P$. akaina, $P$. aspera and $P$. aurora (Cabezas \& Chan, 2014). After the taxonomic rearrangements proposed in the present study the genus Paramunida comprises 40 species (see below).

\section{Paramunida haigae sp. $\mathbf{n}$.}

http://zoobank.org/5ECE748F-15AA-4AF9-9767-866162CB3B58

Figs 1, 2, 3

Material examined. Holotype: Christmas (Kiritimati) Island, Line Islands, Kiribati, $01^{\circ} 51.3^{\prime} \mathrm{N}, 157^{\circ} 30.4^{\prime} \mathrm{W}$, February-March 1973, 183 m (NOAA RV Townsend Cromwell Cruise): male, $16.6 \mathrm{~mm}$ (LACM-CR1973-3312). Paratypes: collected with holotype: 9 males $11.4-17.2 \mathrm{~mm}$ (2 broken), 3 females, $13.5-14.1 \mathrm{~mm}, 2$ ovigerous females, 11.6-14.2 mm (LACM-CR1973-3313).

Description. Carapace: As long as broad, dorsal surface covered with spinules; each spinule usually on short arcuate striae, with few short uniramous setae. Epigastric region with 2 spines, each behind supraocular spine; with median row of spinules behind rostral spine. Mesogastric region with median row of 3 small spines. Anterior branch of cervical groove with short setae. Cervical groove distinct. Cardiac and anterior branchial regions slightly circumscribed. Cardiac region with a median row of 3 small spines, first thicker than others. Each branchial region with row of spines near cardiac region. Frontal margin slightly concave. Lateral margins convex, with some 

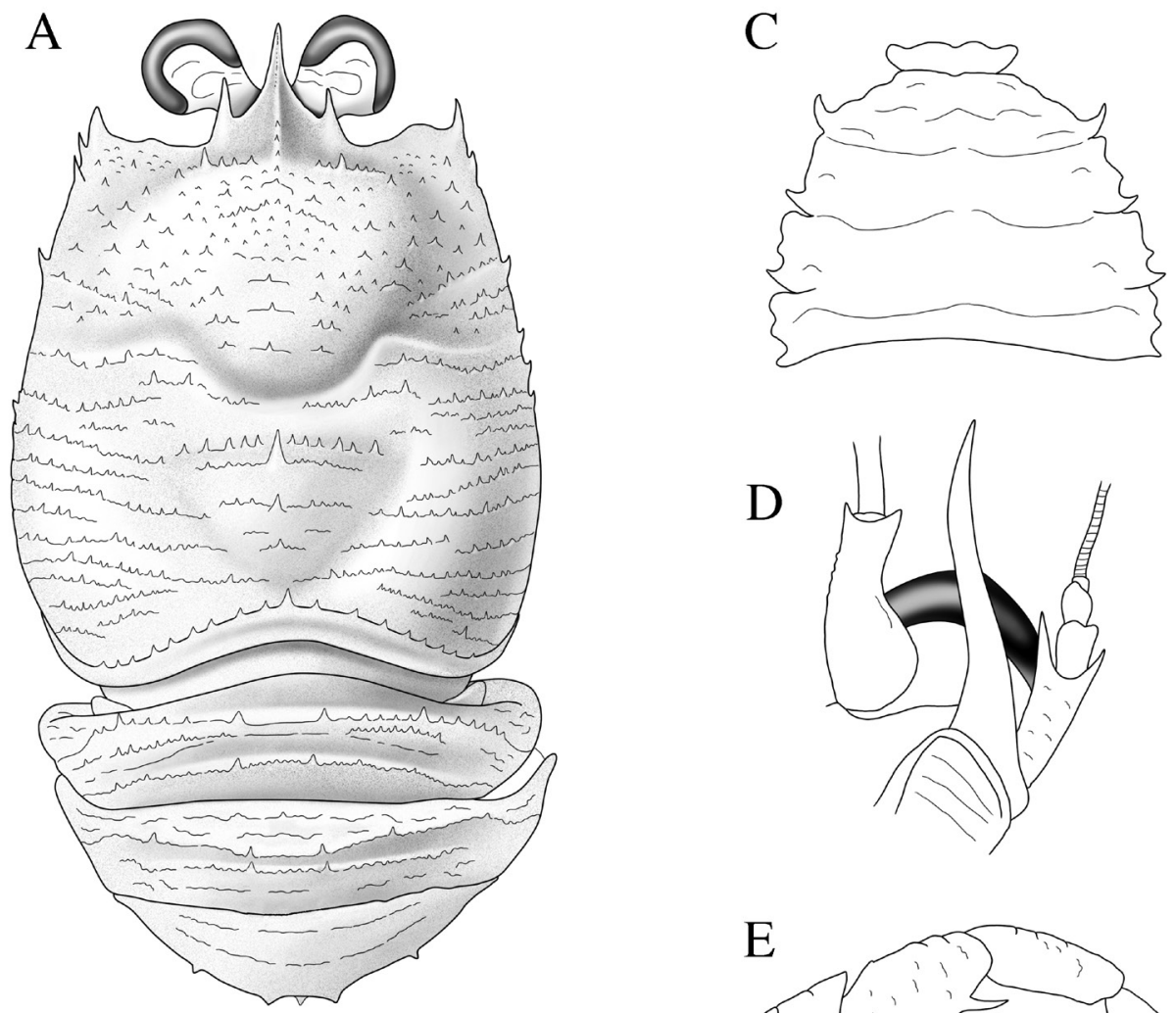

$\mathrm{D}$
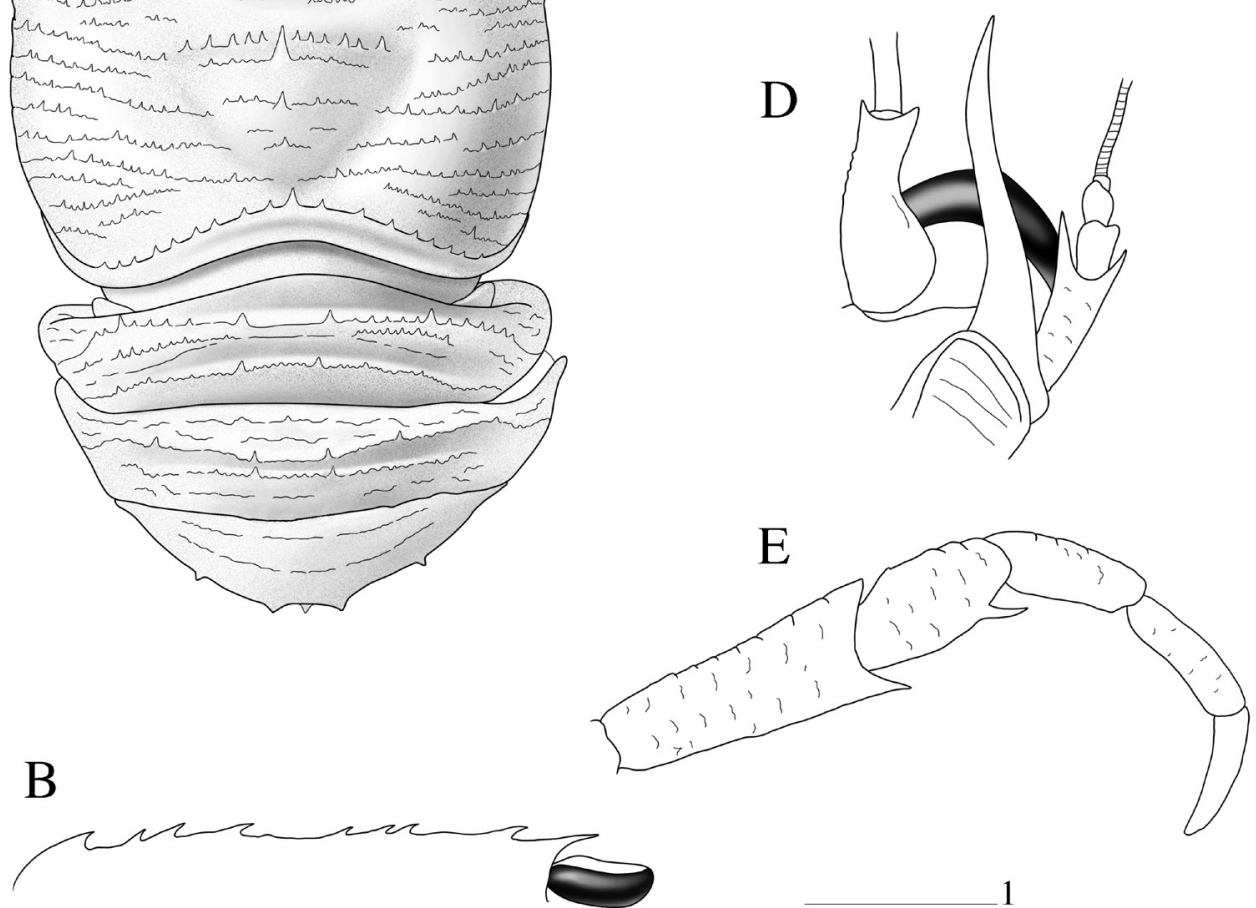

Figure I. Paramunida haigae sp. n. male holotype, 16.6 mm (LACM-CR1973-3312). Christmas (Kiritimati) Island. A carapace and abdomen, dorsal view B carapace, lateral profile $\mathbf{C}$ sternum $\mathbf{D}$ left antennule and antenna, ventral view $\mathbf{E}$ right maxilliped 3, lateral view. Scale: $5 \mathrm{~mm}$ (scale 1 for A-C, E; scale 2 for $\mathbf{D})$.

spines and iridescent setae on anterior half. Anterolateral spine well developed, reaching sinus between rostral and supraocular spines. Rostral spine spiniform, with thin dorsal longitudinal carina; supraocular spines well developed and slender and shorter than rostrum (Figs 1A, B, 3).

Sternum: Thoracic sternite 4 with few arcuate striae; sternites 5-7 smooth (Fig. 1C).

Abdomen: Abdominal somites 2-3 each with 4 well-developed spines on anterior ridge, posterior ridge with 2 median spines. Abdominal somite 4 with 4 spines on an- 
terior ridge; posterior ridge with distinct single median spine. Ridges with numerous spinules and a few small spines (Fig. 1A).

Eyes: Maximum corneal diameter more than one-third distance between bases of anterolateral spines.

Antennule: Article 1 slightly exceeding corneae, with distomesial spine small and as long as distolateral; about twice longer than wide and with fringe of long setae along lateral margin; lateral margin with distal slender portion about half as long as proximal convex portion (Fig. 1D).

Antenna: Anterior prolongation of article 1 overreaching antennular peduncle by about one-third of its length. Article 2 about twice length of article 3 and twice longer than wide, ventral surface with scales; distomesial spine spiniform without tuff of setae, overreaching end of article 3 , not reaching end of antennal peduncle, reaching midlength of anterior prolongation of article 1 , and clearly not reaching end of basal article of antennule, distolateral spine not reaching end of article 3; article 3 about 1.5 times longer than wide and unarmed (Fig. 1D).

Maxilliped 3: Ischium about twice length of merus measured along extensor margin, flexor margin bearing long distal spine; merus with well-developed median spine on flexor margin; extensor margin unarmed (Fig. 1E).

Pereopod 1 (cheliped): Long and slender, squamate, between 6.5-7.5 times carapace length; carpus about as long as palm, and 7-10 times longer than high; palm 1.1-1.5 times fingers length. Base of carpus without bundle of setae (Fig. 2A-C).

Pereopods 2-4 (P2 lacking in holotype): Long and slender, with scales on lateral sides of meri, carpi and propodi; scales with short setae. P2 2.5-3.5 times carapace length, merus 1.1-1.6 times longer than carapace, about 8-10 times as long as high, 4 times as long as carpus and 1.5 times as long as propodus; propodus about 7-10 times as long as high, and 1.4-1.7 times dactylus length. Merus with well-developed spines on extensor margin, increasing in size distally; flexor margin with few spines and one well developed distal spine; row of small spines along flexolateral margin. Carpus with few small extensor spines, small distal spine on extensor and flexor margin. Propodus with small movable flexor spines. Dactylus compressed, slightly curved, with longitudinal carinae along mesial and lateral sides, flexor border unarmed. End of P2 carpus not reaching end of P1 merus. P3 with similar spination and article proportions as P2; propodus slightly longer than $\mathrm{P} 2$ propodus, merus and dactylus as long as those of $\mathrm{P} 2$. P4 as long as P2; merus 1.1-1.3 times carapace length; propodus and dactylus slightly longer than those of $\mathrm{P} 3$; merocarpal articulation clearly exceeding end of anterior prolongation of article1 of antennal peduncle (Fig. 2D-G).

Etymology. This species is dedicated to the renowned carcinologist Janet Haig (1925-1995) who first classified the material examined.

Remarks. Paramunida haigae sp. n. closely resembles $P$. antares Cabezas, Macpherson \& Machordom, 2010 from New Caledonia. The new species is readily separated from $P$. antares in having the rostrum spiniform rather than triangular. Moreover, the mesogastric region in $P$. antares has 3 well-developed spines, but these spines are very small in $P$. haigae sp. $n$. The two species also differ in the article 2 of 


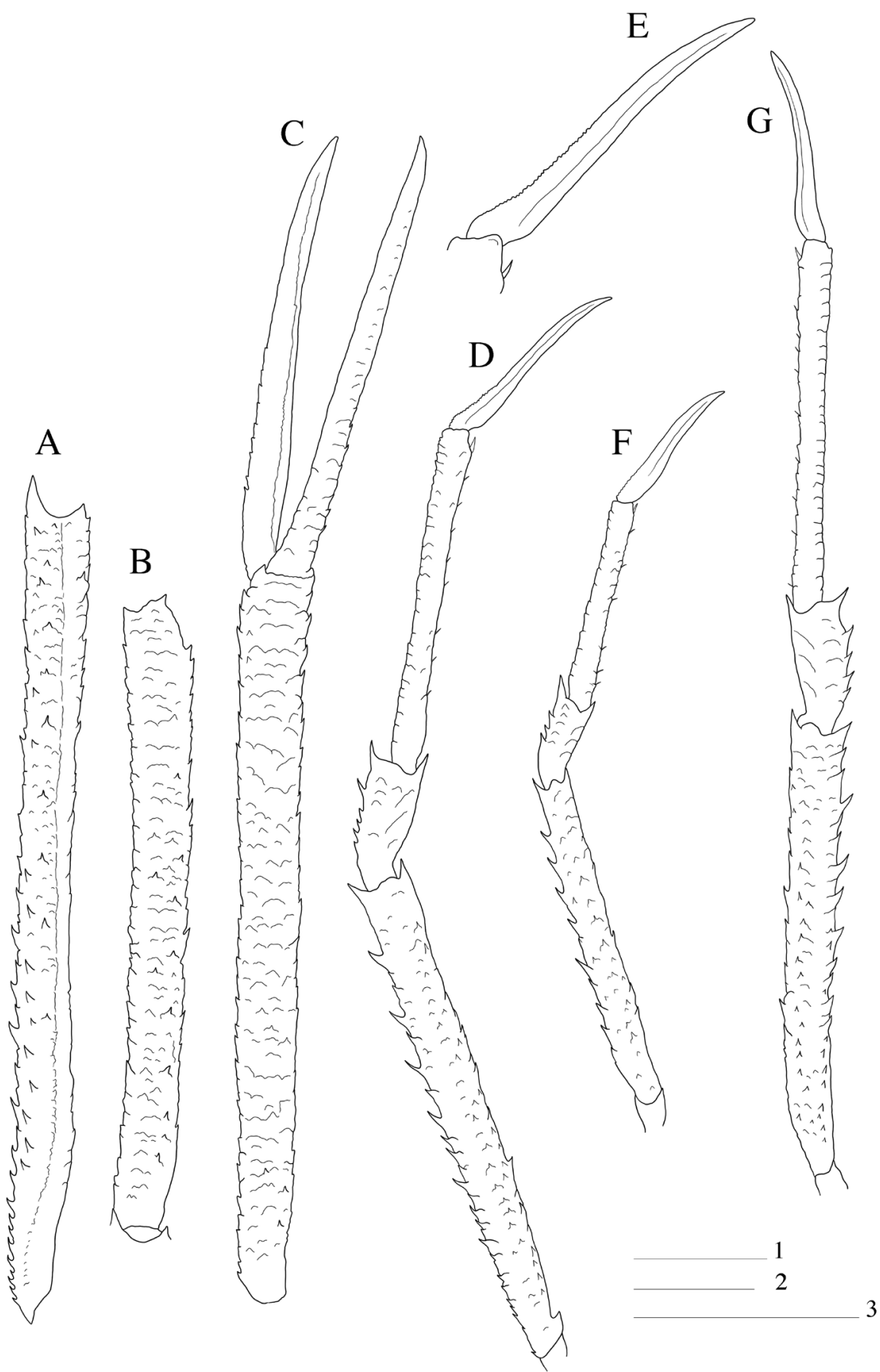

Figure 2. Paramunida haigae sp. n. male holotype, 16.6 mm (LACM-CR1973-3312). Christmas (Kiritimati) Island. A left merus P1, dorsal view $\mathbf{B}$ left carpus P1, dorsal view $\mathbf{C}$ left P1, palm and fingers, dorsal view $\mathbf{D}$ right P3, lateral view $\mathbf{E}$ right P3 dactylus $\mathbf{F}$ male paratype, $11.5 \mathrm{~mm}$ (LACM-CR1973-3313), right P2, lateral view. G left P4, lateral view. Scale: $5 \mathrm{~mm}$ (scale 1 for A-C, D, G; scale 2 for F; scale 3 for $\mathbf{E}$ ). 
the antennal peduncle: twice as long as wide in the new species but only 1.5 times in $P$. antares. Finally, the distomesial spine of antennal article 2 clearly overreaches the end of article 3 in the new species, but this spine only reaches the end of the article 3 in P. antares.

The new species is also very close to $P$. achernar Cabezas, Macpherson \& Machordom, 2010 from Tonga. Paramunida haigae sp. n. can be distinguished from $P$. achernar by having 3 small mesogastric spines (vs. 3 well-developed spines in $P$. achernar). Furthermore, the anterior prolongation of antennal article 1 is clearly longer in $P$. haigae sp. n., overreaching the antennular peduncle by about one-third of its length but only by one-fourth in $P$. achernar, and the distomesial spine of antennal article 2 overreaching the end of article 3 in the new species (vs. only reaching the end of the article 3 in $P$. achernar). Finally, the merocarpal articulation of $\mathrm{P} 3$ clearly exceeds the anterior prolongation of the antennal article 1 in the new species, only slightly exceeding the anterior prolongation in $P$. achernar.

Of the regional Central Pacific Paramunida species, P. haigae sp. n. can be easily distinguished from $P$. hawaiiensis Baba, 1981 from Hawaii in having the rostral spine larger than supraocular spines instead of smaller or at most equal to supraocular spines. Furthermore, the distomesial spine of article 2 reaches end of antennal peduncle in $P$. hawaiiensis but never reaches it in the new species. The new species can also be easily distinguished from P. echinata Macpherson, 1999 from Marquesas Islands in having the rostral spine spiniform instead of triangular. Finally, $P$. haigae sp. $\mathrm{n}$. is also easily distinguishable from $P$. spatula Macpherson, 2006 from the Austral archipelago by the shape of the anterior prolongation of antennal article 1.

Distribution. Christmas (Kiritimati) Island, Kiribati, at $183 \mathrm{~m}$ depth.

\section{Genus Hendersonida gen. n.}

http://zoobank.org/C149D702-673C-48D8-BD97-DD6F20A8B59B

Type species. Munida granulata Henderson, 1885; here designated and by monotypy.

Diagnosis. Carapace as long as wide; dorsal surface granulose, with some scattered spines and small spinules with short uniramous setae and without transverse ridges; few and short setae along anterior branch of cervical groove; posterior margin with some spines; rostrum spiniform, upturned distally, larger and thicker than supraocular spines; supraocular spines small, clearly not reaching midlength of rostrum and falling short the end of corneae; margin between rostral and supraocular spines straight or slightly concave; anterolateral spines well developed situated at front near anterolateral angles, reaching the level between rostrum and supraocular spines; lateral margins with some spines. Eyes large, maximum corneal diameter about half distance between bases of anterolateral spines. Lateral margin of antennular article 1 with distal slender portion about half as long as proximal inflated portion, with 2 distal spines. Antennal peduncle with anterior prolongation of article 1 spiniform; article 2 with distomesial spine long, almost reaching end of anterior prolongation of article 1. P1-P4 long and 
slender, squamate; P2-P4 dactyli slender, curved and unarmed along flexor margin. Male gonopods only present on the second abdominal somites.

Etymology. The generic name Hendersonida acknowledges the meaningful contributions of John Robertson Henderson (1863-1925) to the field of crustacean taxonomy. Gender: feminine.

Remarks. The carapace dorsal surface devoid of distinct transverse ridges or striae, the rostral spine broad at base, the antennal peduncle with a well-developed anterior prolongation of article 1 and the male gonopods absent from the first abdominal link this new genus to Paramunida Baba, 1988. This close relationship has been confirmed by molecular evidence that have rendered this new genus as the sister group of Paramunida (Cabezas et al. 2012, Cabezas and Chan 2014). Hendersonida gen. n. may be easily differentiated from Paramunida by having the dorsal surface of the carapace covered by granules and the distomesial spine of the antennal article 2 almost reaching the end of anterior prolongation of article 1 . The genus contains one species.

\section{Hendersonida granulata (Henderson, 1885)}

Fig. 3

Munida granulata Henderson, 1885: 409 (S of the Fiji Islands, 549 m). - Henderson 1888: 133, pl. 14, figs 3, 3a, 3b (off Matuku, Fiji, 576 m).

Paramunida granulata. - Baba, 1988: 176, fig. 72 (Moluccas off W coast of Halmahera, 545 m). - Macpherson 1993: 452, figs 3, 13 (New Caledonia, Loyalty Islands and Indonesia; reexamination of type material; 439-650 m). - Macpherson 1996: 412 (SW Pacific (Futuna Island, Wallis Islands, Bayonnaise Bank), 400-450 m). Macpherson 2004: 287 (Fiji and Tonga, 395-592 m). - Ahyong and Poore 2004: 68 (Queensland, 548 m). - Baba 2005: 302 (key, synonymies). - Baba et al. 2008: 172 (list of occurrences). - Macpherson and Baba 2011: 60. - Cabezas et al. 2010: 23, fig 13C, 16I (Tonga, Vanuatu, Loyalty Islands, 550-600 m).

Diagnosis. (modified from Cabezas et al. 2010) Rostrum clearly triangular, larger than supraocular spines, with thin dorsal carina; margin between rostral and supraocular spines straight or slightly concave. Minute spinules on gastric and hepatic regions forming groups arising from scale-like striae and with few short uniramous setae. Mesogastric region with 1 well-developed spine. Median cardiac region with 3 or 4 well-developed spines. Few and short setae along anterior branch of cervical groove. Sternal plastron squamate, with numerous striae on sternites 4-7. Lateral margin of antennular article 1 with distal slender portion about half as long as proximal inflated portion. Antennal peduncle with anterior prolongation of article 1 spiniform; article 2 twice longer than broad, with distomesial spine long, almost reaching end of anterior prolongation of article 1, distolateral spine nearly reaching end of article 3; article 31.5 times longer than broad. Base of P1 carpus without bundle of setae. P2 propodus 7-8 times as long as wide, and 1.2-1.3 times longer than dactylus. 

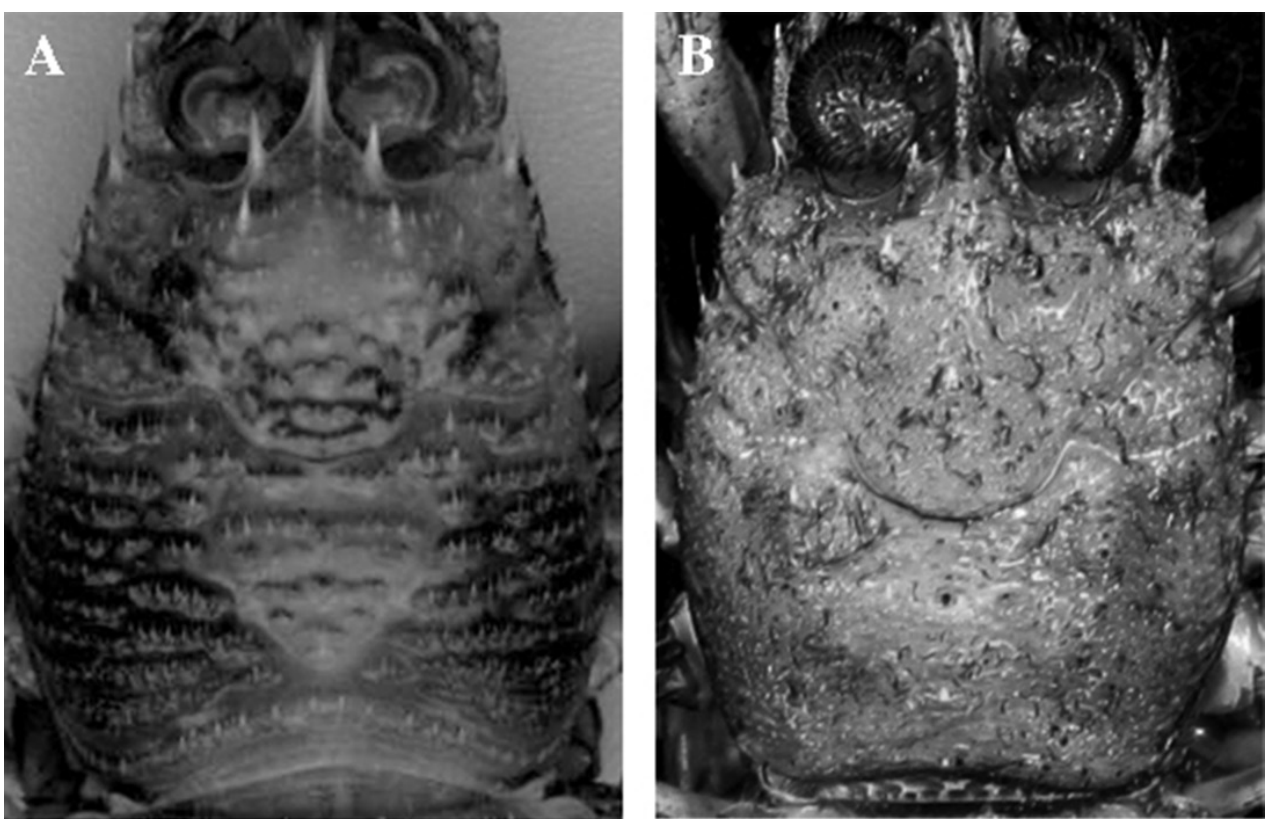

Figure 3. Dorsal surface of the carapace, dorsal view. A Paramunida haigae sp. n., NOAA Townsend Cromwell Cruise, holotype, male $16.6 \mathrm{~mm}$. B Hendersonida granulata, BATHUS 2, Stn CP735, female, $13.7 \mathrm{~mm}$.

Distribution. Philippines, Indonesia, Queensland, New Caledonia, Loyalty Islands, Fiji, Tonga, Futuna Island, Vanuatu, Wallis Islands and Bayonnaise Bank, between 395 and $650 \mathrm{~m}$.

Remarks. Detailed illustrations for H. granulata are included in Baba (1988), Macpherson (1993) and the antennule, antenna and dorsal surface of the carapace were newly illustrated in Cabezas et al. (2010).

\section{Discussion}

The present study updates the taxonomy of the genus Paramunida Baba, 1988 by describing a new species from the Central Pacific Ocean and transferring one species to a new genus. Deep waters in the Central Pacific Ocean have been poorly sampled and our knowledge on diversity of squat lobster fauna is scarce (Baba 2011; Schnabel et al. 2009). The new species herein described, $P$. haigae sp. $n$., represents the fourth record of the genus for Central Pacific waters.

The new genus here described contains only Hendersonida granulata. Although morphologically very similar to Paramunida, recent studies revealed that this species was phylogenetically and genetically very different from the other species of the genus (Cabezas et al. 2010; Cabezas et al. 2012; Cabezas and Chan 2014). This new lineage 


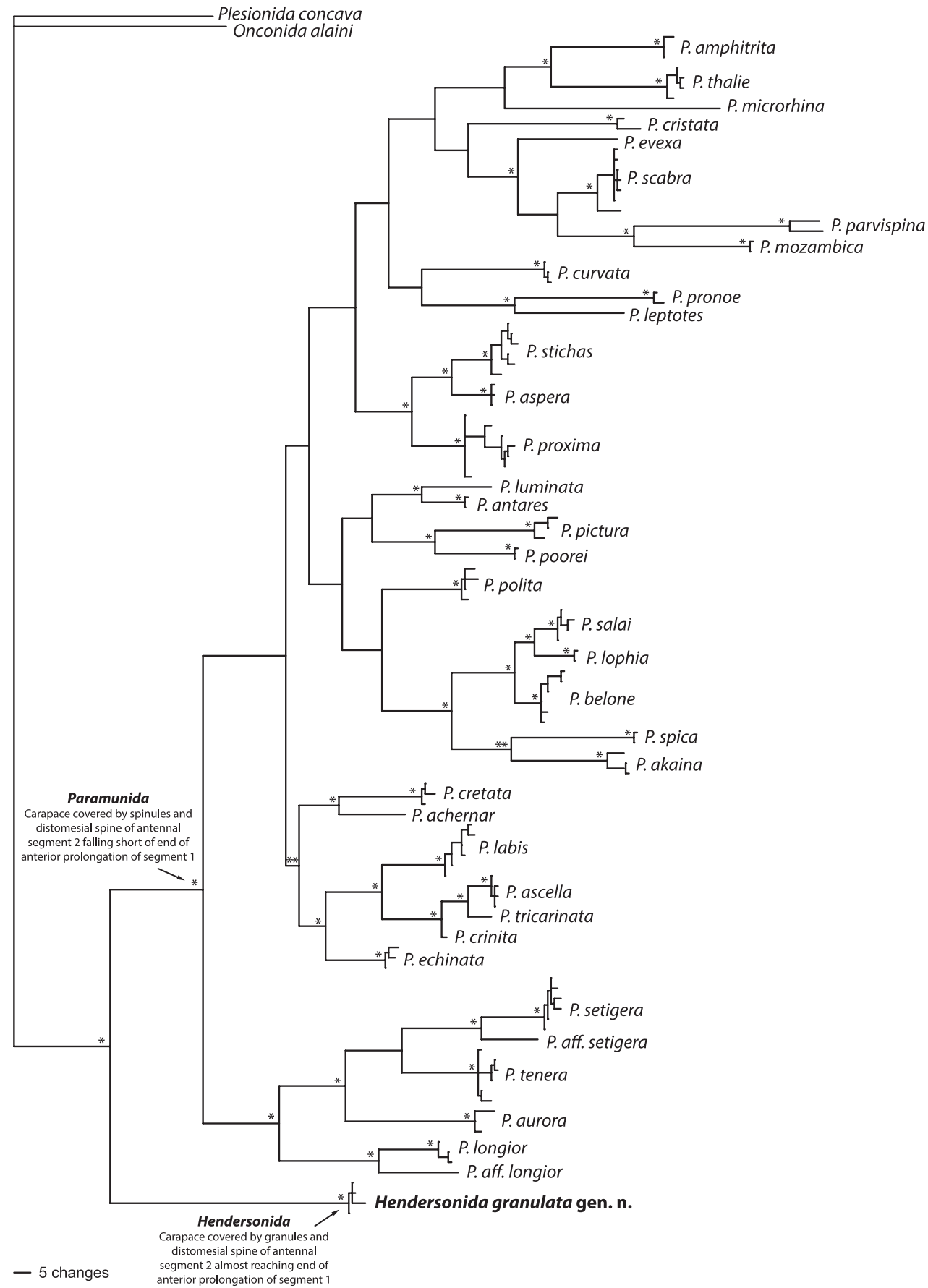

Figure 4. Bayesian tree of the combined dataset $(16 S+$ ND1) as modified from Cabezas and Chan (2014). One asterisk represents $\mathrm{Pp}=1-0.90$ and two asterisks $\mathrm{Pp}=0.70-0.85$. Hendersonida gen. $\mathrm{n}$. is presented in bold. 
possesses two conspicuous diagnostic characteristics that make it easy to differentiate from species of Paramunida: (1) the armature of the dorsal surface of the carapace, and (2) the length of the distomesial spine of antennal article 2. Hendersonida is unique in having a granulated carapace and the distomesial spine of antennal article 2 almost reaching the end of anterior prolongation of article 1 (Cabezas et al. 2010). All other characters present a certain degree of variation among species and they are not useful to distinguish genera. At a molecular level, divergence values between Paramunida and Hendersonida are within the range cited for other squat lobster genera (Cabezas et al. 2008; Machordom and Macpherson 2004), with a mean divergence of $8.05 \%$ for the $16 \mathrm{~S}$ gene, $18.5 \%$ for the ND1 gene and $15.3 \%$ for the COI gene. Furthermore, recent phylogenetic studies including mitochondrial and nuclear markers confirmed $H$. granulata as a highly supported monophyletic clade separated by a long branch from Paramunida s.s. and originated at least 10 mya before the radiation of Paramunida between 21-17 million years ago (Cabezas and Chan 2014; Cabezas et al. 2012). Based on these findings, our decision to designate a new genus is well supported (Fig. 4).

Hendersonida granulata is a widespread species distributed from the Philippines to to Northern Australia and the South Western Pacific, including New Caledonia, Vanuatu, Fiji, Tonga and Wallis and Futuna, between 395 and $650 \mathrm{~m}$. This is unusual, since most deep-sea squat lobsters are characterized by having reduced geographic ranges confined to a single archipelago or a biogeographic area (Schnabel et al. 2011). Previous studies have reported how widely distributed species within deep-sea squat lobsters are most likely to be complexes of species with more restricted distributions (Cabezas et al. 2012; Poore and Andreakis 2011, 2012). For H. granulata only specimens from the South West Pacific (New Caledonia, Vanuatu and Tonga) have been studied in an integrative phylogenetic framework (Cabezas et al. 2012), so future surveys collecting new material through its entire range will help to infer genealogical relationships among geographically distinct populations. The taxonomic rearrangements in this study bring current diversity within Paramunida up to 40 species and up to 21 genera within the family Munididae.

\section{Key to species of Paramunida}

1 Anterior prolongation of antennal article 1 spatulate

P. spatula Macpherson, 2006

- Anterior prolongation of antennal article 1 spiniform .............................2

2 Rostral spine smaller or at most equal to supraocular spines...................... 3

- $\quad$ Rostral spine larger than supraocular spines ....................................8

3 Margin between rostral and supraocular spines clearly convex

P. curvata Macpherson, 2004

Margin between rostral and supraocular spines straight or slightly concave.... 4 Antennal article 2 with minute distomesial spine 
Rostrum spiniform

P. aurora Cabezas \& Chan, 2014

Sternal plastron with numerous striae. Bundle of setae at base of carpus of P1 present.

P. setigera $\mathrm{Baba}, 1988$

Sternal plastron with few striae on each side of sternites 5-7. Bundle of setae at base of carpus of $\mathrm{P} 1$ absent.

P. tenera Cabezas, Macpherson \& Machordom, 2010

Distomesial spine of antennal article 2 mucronated or bluntly produced ... 10

Distomesial spine of antennal article 2 spiniform

Mesogastric region with a median row of 3 or 4 distinct spines

Distomesial spine of antennal article 2 clearly overreaching antennal peduncle

Distomesial spine of antennal article 2 nearly reaching end of antennal peduncle.....

Distolateral spine of antennal article 2 overreaching end of article 3

P. belone Macpherson, 1993

Distomesial spine of antennal article 2 slightly or clearly overreaching antennal peduncle.....

Distomesial spine of antennal article 2 never reaching end of antennal peduncle

Lateral margin of antennular article 1 with distal slender portion as long as proximal inflated portion....... P. spica Cabezas, Macpherson \& Machordom, 2010 Lateral margin of antennular article 1 with distal slender portion about half as long as proximal inflated portion

\section{Distolateral spine of antennal article 2 exceeding antennal article 3}

P. salai Cabezas, Macpherson \& Machordom, 2009

Distolateral spine of antennal article 2 not reaching end of antennal article 3 ... 17

17 Mesial margin of antennal article 2, including distal spine, straight. Rostrum triangular or spiniform.

- Mesial margin of antennal article 2, including distal spine, convex. Rostrum spiniform 
Rostrum triangular .. P. ascella Cabezas, Macpherson \& Machordom, 2010 Rostrum spiniform

P. mozambica Cabezas, Macpherson \& Machordom, 2010

19 Distomesial spine of antennal article 2 shorter than rest of article 2. Gastric region with short striae. Antennal article 3 about 1.5 times longer than broad

P. stichas Macpherson, 1993

Distomesial spine of antennal article 2 as long as rest of article 2. Gastric region with moderate-sized striae. Antennal article 3 about twice longer than broad P. lophia Cabezas, Macpherson \& Machordom, 2009 Mesogastric region without well-developed spines

P. parvispina Cabezas, Macpherson \& Machordom, 2010

Sternal plastron with numerous striae. Article 2 of antennal peduncle bluntly produced distomesially

P. evexa Macpherson, 1993 Sternal plastron with few striae, sternites 5-7 with few striae on each side. Article 2 of antennal peduncle produced distomesially ending in distinct spine .........22 Rostrum triangular. Propodus of walking legs more than 1.5 times dactylus length ...... P. echinata Macpherson, 1999 Rostrum spiniform. Propodus of walking legs slightly longer than dactylus .. P. labis Macpherson, 1996 Rostrum with thick dorsal carina P. cristata Macpherson, 2004 Rostrum with thin dorsal carina.

Distomesial spine of antennal article 2 clearly exceeding antennal peduncle ... P. leptotes Macpherson \& Baba, 2009 Distomesial spine of antennal article 2 at most reaching end of antennal peduncle.

Mesogastric region with a row of 3 or 4 distinct spines

Median cardiac region with 1 spine

P. pronoe Macpherson, 1993 Median cardiac region with a row of 3 or 4 spines

Tufts of long and dense setae along anterior branch of cervical groove.

P. crinita Cabezas, Macpherson \& Machordom, 2010

Few and short setae along anterior branch of cervical groove Sternal plastron with few striae, sternites 5-7 only with few striae on each lateral side. P. polita Macpherson, 1993 Sternal plastron with numerous striae. P. scabra (Henderson, 1885) Sternal plastron with numerous striae

Sternal plastron with few striae, sternites 5-7 only with few striae on each lateral side.

Antennal article 3 twice as long as broad. Few and short setae along anterior branch of cervical groove.... .P. thalie Macpherson, 1993 Antennal article 3 slightly longer than broad. Tufts of long and dense setae along anterior branch of cervical groove 
31 Distomesial spine of antennal article 2 reaching or slightly exceeding end of antennal peduncle. Distolateral spine of antennal article 2 reaching or slightly exceeding end of antennal article 3 .....

- Distomesial spine of antennal article 2 not reaching end of antennal peduncle. Distolateral spine of antennal article 2 not reaching end of antennal article 3 ....

32 Antennal article 3 as long as wide P. aspera Cabezas \& Chan, 2014 Antennal article 3 about 1.5 times longer than wide

P. marionis Cabezas, Macpherson \& Machordom, 2010

33 Antennal article 3 more than twice longer than broad.

P. amphitrita Macpherson, 1996

$-$

Antennal article 3 as long as broad or at most 1.5 times longer than broad.... 34

$-$ Antennal article 2 as long as or more than 3 times longer than broad .......35 Antennal article 2 at most twice longer than broad

35 Distomesial spine of antennal article 2 reaching or slightly overreaching end of antennal article 3. Spinules on gastric and hepatic regions mostly forming groups arising from scale-like striae.... P. pictura Macpherson, 1993

- Distomesial spine of antennal article 2 not reaching end of antennal article 3. Spinules on gastric and hepatic regions mostly not in groups, lacking scaly striae P. poorei Cabezas, Macpherson \& Machordom, 2010

36 Antennal article 2 slightly longer than broad...P. cretata Macpherson, 1996 Antennal article 2 twice longer than broad.

37 Row of small epigastric spines behind rostral spine absent

P. luminata Macpherson, 1996

- $\quad$ Row of small epigastric spines behind rostral spine present

38 Rostrum triangular... P. antares Cabezas, Macpherson \& Machordom, 2010

- $\quad$ Rostrum spiniform 39

39 Mesogastric region with 3 small spines. Merocarpal articulation of P3 clearly exceeding end of anterior prolongation of antennal article $1 \ldots P$. haigae sp. $\mathbf{n}$. Mesogastric region with 3 well-developed spines. Merocarpal articulation of P3 slightly exceeding end of anterior prolongation of antennal article.....

P. achernar Cabezas, Macpherson \& Machordom, 2010

\section{Acknowledgements}

We are very grateful to A. Crosnier, P. Bouchet, L. Corbari, and B. Richer de Forges for their support and for making Paramunida material available to us. Thanks are also due to Annie Machordom for her constant support and guidance with previous studies on Paramunida and J. Macpherson for technical assistance with illustrations. Finally, the first author would like to express sincere gratitude to Adam Wall, Regina Wetzer and Dean Pentcheff for the opportunity to study the squat lobster material at Los Angeles County Museum of Natural History and making her visit so delightful. PC was funded by Research and Collections, Natural History Museum of Los Angeles County. 


\section{References}

Ahyong ST (2007) Decapod Crustacea collected by the NORFANZ Expedition: Galatheidae and Polychelidae. Zootaxa 1593: 1-54.

Ahyong ST, Baba K, Macpherson E, Poore GCB (2010) A new classification of the Galatheoidea (Crustacea: Decapoda: Anomura). Zootaxa 2676: 57-68.

Ahyong ST, Poore GCB (2004) Deep-water Galatheidae (Crustacea: Decapoda: Anomura) from southern and eastern Australia. Zootaxa 472, 3-76.

Alcock A (1894) Natural history notes from H.M. Royal Indian Marine Survey Steamer "Investigator", commander R.F. Hoskin, R.N., commanding. Series II, No. 1.On the results of deep-sea dredging during the season of 1890-91 (continued). Annals and Magazine of Natural History (ser. 6) 13: 321-334.

Baba K (1981) A new galatheid crustacean (Decapoda, Anomura) from the Hawaiian Islands. Journal of Crustacean Biology 1: 288-292. doi: 10.2307/1548167

Baba K (1988) Chirostylid and galatheid crustaceans (Decapoda: Anomura) of the "Albatross" Philippine Expedition, 1907-1910. Researches on Crustacea, Special Number 2: 1-203.

Baba K (2005) Deep-sea chirostylid and galatheid crustaceans (Decapoda: Anomura) from the Indo-West Pacific, with a list of species. Galathea Reports 20:1-317.

Baba K, Macpherson E, Lin CW, Chan TY (2009) Crustacean Fauna of Taiwan. Squat lobsters (Chirostylidae and Galatheidae). National Taiwan Ocean University, Keelung, 311 pp.

Baba K (2011) Babamunida debrae, a new species of squat lobster (Crustacea: Anomura: Galatheoidea: Munididae) from the Hawaiian Islands. Zootaxa 2812: 21-27.

Baba K, Ahyong ST, Macpherson E (2011) Morphology of marine squat lobsters. In: Poore G, Ahyong S, Taylor J (Eds) The Biology of Squat Lobsters. CSIRO Publishing, Australia, 1-39.

Baba K, Macpherson E, Poore GCB, Ahyong ST, Bermudez A, Cabezas P, Lin CW, Nizinski M, Rodrigues C, Schnabel KE (2008) Catalogue of squat lobsters of the world (Crustacea: Decapoda: Anomura-families Chirostylidae, Galatheidae and Kiwaidae). Zootaxa 1905: 1-220. doi: 10.1651/07-2823R.1

Cabezas P, Chan TY (2014) Deep-sea squat lobsters of the genus Paramunida Baba, 1988 (Crustacea: Decapoda: Munididae) from the Philippines Panglao 2004, Panglao 2005 and Aurora 2007 expeditions, with the description of three new species. Raffles Bulletin of Zoology 62: 302-316.

Cabezas P, Macpherson E, Machordom A (2008) A new genus of squat lobster (Decapoda: Anomura: Galatheidae) from the South West Pacific and Indian Ocean inferred from morphological and molecular evidence. Journal of Crustacean Biology 28: 68-75. doi: 10.1651/07-2823R.1

Cabezas P, Macpherson E, Machordom A (2009) Morphological and molecular description of new species of squat lobster (Crustacea: Decapoda: Galatheidae) from the Solomon and Fiji Islands (South-West Pacific). Zoological Journal of the Linnean Society 156: 465493. doi: 10.1111/j.1096-3642.2008.00492.x

Cabezas P, Macpherson E, Machordom A (2010) Taxonomic revision of the genus Paramunida Baba, 1988 (Crustacea: Decapoda: Galatheidae): a morphological and molecular approach. Zootaxa 2712: 1-60. 
Cabezas P, Sanmartín I, Paulay G, Macpherson E, Machordom A (2012) Deep under the sea: unraveling the evolutionary history of the dep-sea squat lobster Paramunida (Decapoda: Munididae). Evolution 66: 1878-1896. doi: 10.1111/j.1558-5646.2011.01560.x

Henderson JR (1885) Diagnoses of new species of Galatheidae collected during the "Challenger" expedition. Annals and Magazine of Natural History (ser 5) 16: 407-421.

Henderson JR (1888) Report on the Anomura collected by H.M.S. Challenger during the years 1873-76. Report on the Scientific Results of the Voyage of H.M.S Challenger during the years 1873-76. Zoology, 27: 1-221, 21 pls.

Leach WE (1820) Galatéadées. Dictionnaire des Sciences Naturelles. F. G. Levreault, Paris, 49-56.

Machordom A, Macpherson E (2004) Rapid radiation and cryptic speciation in galatheid crabs of the genus Munida and related genera in the South West Pacific: molecular and morphological evidence. Molecular Phylogenetics and Evolution 33: 259-279. doi: 10.1016/j. ympev.2004.06.001

Macpherson E (1993) Crustacea Decapoda: species of the genus Paramunida Baba, 1988 (Galatheidae) from the Philippines, Indonesia and New Caledonia. In: Crosnier A (Ed) Résultats des Campagnes MUSORSTOM, volume 10. Mémoires du Muséum National d'Histoire Naturelle, Paris 156: 443-473.

Macpherson E (1996) Crustacea Decapoda: new records of species of the genera Munida Leach, 1820 and Paramunida Baba, 1988 (Galatheidae) from New Caledonia, with the descriptions of three new species. In: Crosnier A (Ed) Résultats des Campagnes MUSORSTOM, volume 15. Mémoires du Muséum National d'Histoire Naturelle, Paris 168: 423-431.

Macpherson E (1999) Crustacea Decapoda: species of the genera Crosnierita Macpherson, 1998, Munida Leach, 1820, and Paramunida Baba, 1988 (Galatheidae) collected during the MUSORSTOM 9 cruise to the Marquesas Islands. In: Crosnier A (Ed) Résultats des Campagnes MUSORSTOM, volume 21. Mémoires du Muséum National d'Histoire Naturelle, Paris 184: 415-423.

Macpherson E (2004) Species of the genus Munida Leach, 1820 and related genera from Fiji and Tonga (Crustacea: Decapoda: Galatheidae). In: Marshall BA, Richer de Forges B (Eds) Tropical Deep-Sea Benthos, volume 23. Mémoires du Muséum National d'Histoire Naturelle, Paris 191: 231-292.

Macpherson E (2006) Galatheidae (Crustacea, Decapoda) from the Austral Islands, Central Pacific. In: Richer de Forges B, Justine JL (Eds) Tropical Deep-Sea Benthos. Volume 24. Mémoires du Muséum National d'Histoire Naturelle, Paris 193: 285-333.

Macpherson E, Baba K (2009) New species of squat lobsters of the genera Agononida and Paramunida (Crustacea: Decapoda: Anomura: Galatheidae) from the western Pacific. Zootaxa 2024: 56-68.

Macpherson E, Baba K (2011) Taxonomy of squat lobsters. In: Poore G, Ahyong S, Taylor J (Eds) The Biology of Squat Lobsters. CSIRO Publishing, Australia, 40-73.

Macpherson E, Robainas-Barcia A (2013) A new genus and some new species of the genus Lauriea Baba, 1971 (Crustacea, Decapoda, Galatheidae) from the Pacific and Indian Oceans, using molecular and morphological characters. Zootaxa 3599: 136-160. doi: 10.11646/ zootaxa.3599.2.2 
Poore GCB (2004) Marine decapod Crustacea of southern Australia. A guide to identification (with chapter on Stomatopoda by Shane Ahyong). CSIRO Publishing, Melbourne, 574 pp. Poore GCB, Andreakis N (2011) Morphological, molecular and biogeographic evidence support two new species in the Uroptychus naso complex (Crustacea: Decapoda: Chirostylidae). Molecular Phylogenetics and Evolution 60: 152-169. doi: 10.1016/j.ympev.2011.03.032 Poore GCB, Andreakis N (2012) The Agononida incerta species complex unravelled (Crustacea: Decapoda: Anomura: Munididae). Zootaxa 3492: 1-29.

Richer de Forges B, Chan TY, Corbari L, Lemaitre R, Macpherson E, Ahyong ST, Ng PKL (2013) The MUSORSTOM-TDSB deep-sea benthos exploration programme (19762012): An overview of crustacean discoveries and new perspectives on deep-sea zoology and biogeography. In: Ahyong ST, Chan TY, Ng PKL (Eds) Tropical Deep-Sea Benthos. Volume 27. Mémoires du Muséum National d'Histoire Naturelle, Paris, 13-66.

Schnabel KE, Ahyong ST (2010) A new classification of the Chirostyloidea (Crustacea: Decapoda: Anomura). Zootaxa 2687: 56-64.

Schnabel KE, Martin JW, Moffitt RB (2009) Additions to the decapod crustacean fauna of the Hawaiian Islands, III. A new species of the genus Babamunida (Crustacea: Galatheidae) from Hawaii based on morphological and molecular evidence. Zootaxa 2130: 21-30.

Schnabel KE, Cabezas P, McCallum A, Macpherson E, Ahyong ST, Baba K (2011) Worldwide distribution patterns of squat lobsters. In: Poore G, Ahyong S, Taylor J (Eds) The Biology of Squat Lobsters. CSIRO Publishing, Australia, 149-182. 